\title{
Competências e habilidades do profissional contábil: o que pensam os estudantes de administração e ciências contábeis?
}

\author{
Competencies and skills of the accounting professional: what do administration and accounting \\ students think?
}

Competencias y habilidades del profesional contable: ¿qué piensan los estudiantes de administración y contabilidad?

Cíntia Vanessa Monteiro Germano Aquino ORCID: https://orcid.org/0000-0002-4317-6773 Universidade Estadual Vale do Acaraú, Brasil E-mail: cintiavmg@gmail.com

Marcos Bruno Messias de Sousa ORCID: https://orcid.org/0000-0002-8335-7181 Universidade Estadual Vale do Acaraú, Brasil E-mail: marcossousa82515@gmail.com

Clayton Robson Moreira da Silva ORCID: https://orcid.org/0000-0003-0717-2713 Instituto Federal de Educação, Ciência e Tecnologia do Piauí, Brasil E-mail: claytonrmsilva@gmail.com

Joelma Leite Castelo

ORCID: https://orcid.org/0000-0002-3457-6185 Universidade Estadual do Ceará, Brasil E-mail: joelma.castelo@uece.br

Bruno Mendes Pereira

ORCID: https://orcid.org/0000-0003-4678-1394

Universidade do Vale do Rio dos Sinos, Brasil E-mail: bruno.bmp@outlook.com

\begin{abstract}
Resumo
Essa pesquisa teve como objetivo analisar a percepção dos discentes dos cursos de administração e ciências contábeis sobre competências e habilidades do profissional contábil. Para tanto, foram aplicados questionários com 237 estudantes de uma universidade pública no Estado do Ceará. O instrumento de coleta de dados foi adaptado do estudo de Reis, Sedivama, Moreira e Moreira (2015). Os dados foram analisados por meio dos métodos de evocação de palavras, análise descritiva e teste Mann-Whitney. Os resultados, com base na evocação de palavras, sugerem que os alunos do curso de administração apontaram mais características relacionadas às "habilidades intelectuais e do conhecimento", enquanto os alunos de ciências contábeis evocaram mais palavras relacionadas às "habilidades e competências pessoais", já o conjunto de competências menos citado pelos estudantes de ambos os cursos foi em relação às "habilidades e competências organizacionais e relação interpessoal". O teste Mann-Whitney evidenciou diferenças estatísticas entre os grupos de respondentes, com destaque para as diferenças entre as percepções dos estudantes dos diferentes cursos, sugerindo que, de fato, os alunos de administração e de ciências contábeis têm percepções diferentes em relação às competências e habilidades do profissional contábil.
\end{abstract}

Palavras-chave: Competências e habilidades; Profissional contábil; Administração; Ciências contábeis.

\begin{abstract}
This research aimed to analyze the perception of administration and accounting students about competencies and skills of the accounting professional. Therefore, questionnaires were applied to 237 students from a public university in the State of Ceará. The data collection instrument was adapted from the study by Reis, Sedivama, Moreira and Moreira (2015). Data were analyzed using words evocation method, descriptive analysis and Mann-Whitney test. The results, based on the words evocation, suggest that the administration students pointed out more characteristics related to "intellectual and knowledge skills", while the accounting students evoked more words related to "personal skills and competencies". The set of competencies least mentioned by students in both courses was in relation to "organizational skills and competencies and interpersonal relationships". The Mann-Whitney test showed statistical differences between the groups of respondents, highlighting the differences between the perceptions of students from different courses, suggesting that, in fact, administration and accounting students have different perceptions regarding competencies and skills of the accounting professional.
\end{abstract}

Keywords: Competencies and skills; Accounting professional; Administration; Accounting. 


\begin{abstract}
Resumen
Esta investigación tuvo como objetivo analizar la percepción de los estudiantes de administración y ciencias contables sobre las competencias y habilidades del profesional contable. Por lo tanto, se aplicaron cuestionarios a 237 estudiantes de una universidad pública del estado de Ceará. El instrumento de recolección de datos fue adaptado del estudio de Reis, Sedivama, Moreira y Moreira (2015). Los datos se analizaron mediante métodos de evocación de palabras, análisis descriptivo y prueba de Mann-Whitney. Los resultados, basados en la evocación de palabras, sugieren que los estudiantes del curso de administración señalaron más características relacionadas con "habilidades intelectuales y de conocimiento", mientras que los estudiantes de ciencias contables evocaron más palabras relacionadas con "habilidades y competencias personales". Lo menos mencionado por los estudiantes en ambos cursos fue en relación a "habilidades y competencias organizativas y relaciones interpersonales". La prueba de MannWhitney mostró diferencias estadísticas entre los grupos de encuestados, destacando las diferencias entre las percepciones de los estudiantes de diferentes cursos, sugiriendo que, de hecho, los estudiantes de administración y contabilidad tienen diferentes percepciones sobre las competencias y habilidades del profesional contable.
\end{abstract}

Palabras clave: Competencias y habilidades; Profesional contable; Administración; Contabilidad.

\title{
1. Introdução
}

Os ambientes organizacionais e educacionais demandam novas perspectivas na formação dos profissionais, em especial o profissional contábil, dado o acelerado processo de inovações tecnológicas, significativo crescimento do número de programas de pós-graduação stricto sensu e adoção das normas internacionais de contabilidade, exigindo dos profissionais contábeis novas habilidades e competências (Martins, Martins \& Morais, 2019; Amorim, 2017; Leal, Miranda, Araújo \& Borges, 2014). Destaca-se que o aumento na busca pela profissão contábil por parte dos estudantes tem se dado em função das oportunidades de carreira, bem como pela necessidade latente de profissionais qualificados nesta área (Samsuri, Arifin \& Hussin, 2016).

Por outro lado, embora alguns estudos que analisaram os estereótipos do profissional contábil indiquem características positivas como habilidade de comunicação, ética e propensão ao risco (Leal et al., 2014), ainda há predominância de uma visão distorcida deste profissional, com destaque para características negativas como: muito burocrático, pouco criativo, focado em números (Smith \& Jacobs, 2011; Martins, Martins \& Morais, 2019), frio, introvertido e antissocial (Mbawuni, 2015; Wessels \& Steenkamp, 2009). Tais características têm ajudado a construir uma imagem do contador que, de modo geral, não tem sido muito atrativa para os estudantes (Leal et al., 2014).

Desse modo, compreende-se que a imagem do profissional contábil tem se desgastado nos últimos tempos (Mbawuni, 2015), e que as percepções equivocadas e estereotipadas que o público em geral forma sobre o profissional contábil acabam por sugerir irrelevância de seu trabalho, o que provoca questionamentos sobre suas competências e habilidades (Hunt, Falgiani \& Intrieri, 2004). No entanto, observa-se que muitas destas características não estão em consonância com as habilidades exigidas dos profissionais da contabilidade moderna, que devem estar constantemente em contato com as pessoas e abertos a resolver problemas (Wessels \& Steenkamp, 2009).

Do ponto de vista da atuação profissional, destaca-se que os diálogos estabelecidos entre as ciências contábeis e a administração evidenciam uma prática interdisciplinar, proporcionando conhecimentos de várias áreas no processo de ensinoaprendizagem, bem como uma visão ampla de cenários e fenômenos do mundo contemporâneo (Borges \& Naves, 2014). Estudos que exploram a percepção dos discentes de administração e contabilidade buscam compreender diversos assuntos de interseção entre essas duas áreas, sejam assuntos relacionados ao ensino ou à prática profissional (Soares et al, 2019; Dani et al., 2017; Cunha, De Luca, Lima, Cornacchione Jr. \& Ott, 2015; Borges \& Mafra, 2013; Tibola, Silveira \& Mais, 2012).

Nessa perspectiva, este estudo analisa a percepção dos discentes dos cursos de administração e ciências contábeis sobre competências e habilidades do profissional contábil. Para tanto, realizou-se um estudo em uma universidade estadual, situada no Estado do Ceará, pioneira na oferta dos cursos de ciências contábeis e administração no interior do estado, sendo responsável pela formação de um vasto contingente de profissionais dessas áreas. 
O presente estudo justifica-se por sua abordagem interdisciplinar focada na análise da percepção dos discentes tanto de administração quanto de contabilidade sobre o conhecimento e habilidade do profissional contábil, configurando-se uma proposta relevante e pouco explorada (Leal et al., 2014). Compreende-se ainda que a abordagem interdisciplinar valoriza a importância do estudo no campo acadêmico e teórico que envolvem as ciências contábeis e a administração (Borges \& Naves, 2014), uma vez que esses profissionais tendem a atuar de forma conjunta, sendo relevante a compreensão e percepção do campo de atuação um do outro. Além disso, observa-se que a percepção dos discentes em relação à profissão influencia na sua decisão em relação à área que deseja atuar, criando expectativas quanto ao mercado de trabalho (Araújo \& Santana, 2008).

Do mesmo modo, dada a preocupação com as necessidades do mercado de trabalho na área contábil, exigidas pelas constantes mudanças no ambiente organizacional (Ott, Cunha, Cornachione \& De Luca, 2011), essa pesquisa visa ampliar o debate sobre a temática no âmbito acadêmico e organizacional.

\section{Competências e Habilidades do Profissional Contábil}

O termo competência origina-se da palavra em latim competentia, que significa a aptidão de quem é hábil em apreciar e resolver determinada questão, de fazer determinada coisa, com capacidade, habilidade, aptidão e idoneidade (Cardoso, Riccio \& Albuquerque, 2009). Também pode ser compreendida como uma mistura complexa de habilidade, atitude, experiência, motivação e interesse, sustentada pela capacidade de aprender e aplicar esse aprendizado aos desafios que o trabalho demanda (Tan \& Laswad, 2018).

Definições de competências de empregabilidade são comumente denominadas como habilidades genéricas, habilidades não-técnicas, capacidades, competências essenciais, habilidades pessoais transferíveis, habilidades sociais e atributos (Tan \& Laswad, 2018) e são consideradas relevantes tanto para o nível básico quanto para funcionários estabelecidos (O'Connell et al., 2015; Watty et al., 2012).

Por sua vez, o termo habilidade origina-se da palavra em latim habilitate, que significa saber fazer, preenchendo a lista de competências das empresas (Cardoso, Riccio, Mendonça \& Ovadomari, 2010). Desse modo, os autores argumentam que o saber agir não se submete apenas a preocupação de resolver um problema, mas também a se antecipar e evitar que tal inconveniência venha ocorrer. A habilidade caracteriza-se quando o indivíduo tem a capacidade de realizar algo, como classificar, montar, calcular, ler, observar, interpretar, identificar variáveis, compreender fenômenos, relacionar informações, analisar situações-problema, sintetizar, julgar, correlacionar e manipular (Cardoso et al., 2010; Gomes, 2003).

Faz-se necessário observar as competências e habilidades, que podem ser específicas do contexto ou da disciplina, para que o profissional alcance a capacidade de rede e de comercializar a si mesmo, navegar por uma carreira e permanecer empregável, sendo estas competências e habilidades modificadas ao longo do tempo conforme a natureza do trabalho (Tan \& Laswad, 2018; Department of Education, Employment and Workplace Relations [DEEWR], 2012).

Pesquisas sobre habilidades e competências exigidas de contadores começaram na década de 1980 nos Estados Unidos (Asonitou \& Hassall, 2019) enfatizando a lacuna de expectativa de desempenho entre as práticas e a educação contábil (American Institute of Contadores Públicos Certificados [AICPA], 2018). Habilidades ou atributos genéricos de graduação abrangem habilidades e conhecimentos de graduados universitários, além do conhecimento de conteúdo da disciplina, que são aplicáveis a uma variedade de contextos (Barrie, 2012; Asonitou \& Hassall, 2019).

Órgãos profissionais e formuladores de política destacaram a mudança na profissão contábil devido à evolução da tecnologia, à mudança das práticas de gestão, à competitividade internacional e à "sociedade do conhecimento", afetando significativamente a forma de execução de suas tarefas, bem como os campos de atuação da profissão contábil: contabilidade financeira, contabilidade gerencial, auditoria, tributação e contabilidade pública (Howieson, 2003; International Federation of Contadores [IFAC], 2010). 
Na concepção de Schlindwein (2007), os profissionais contábeis do mundo moderno precisam desenvolver várias outras aptidões. Portanto, o autor ressalta que, para exercer com bom desempenho a carreira, o profissional contábil deverá ter iniciativa, coragem, ética, visão de futuro, negociação, agilidade, segurança para solucionar problemas de forma dinâmica, flexível e com boa capacidade de inovação, sobretudo, na sua área de atuação. Desse modo, as Instituições de Ensino Superior (IES) devem atualizar e revisar de forma constante os programas de ensino para inserir competências e habilidades que permitam o reconhecimento internacional dos profissionais contadores (Ott et al., 2011).

No âmbito internacional, padrões de competências profissionais foram elaborados. No cenário norte-americano, a entidade American Institute of Certified Public Accountants (AICPA), organizou o Core Competency Framework (AICPA, 2018), que propõe um modelo de padrão de competências que devem ser desenvolvidas pelos profissionais em sua inserção no mercado de trabalho, classificadas em:

a) competências contábeis: englobam a avaliação; análise e gestão de riscos; análise e interpretação de medições; relatórios, pesquisa, gerenciamento de sistema e processo; tecnologia e ferramentas relevantes para analisar dados com eficiência e eficácia nas operações;

b) competências empresariais: descrevem as perspectivas estratégicas globais e industriais; gestão de processos e pesquisas; governança e perspectiva do cliente, desenvolvendo o entendimento dos ambientes legais e regulamentares que afetam uma organização, identificando suas necessidades, compreendendo as mudanças relevantes no ambiente e no mercado; e,

c) competências profissionais: evidenciam a conduta ética; o comportamento profissional na tomada decisão de forma colaborativa, destacando a liderança, comunicação e gerenciamento de projetos por meio da utilização efetiva do tempo e de outros recursos com o propósito do alcance dos objetivos e do desempenho organizacional.

Percebe-se que tais padrões de competências destacam uma ampla gama de habilidades não-técnicas exigidas pelos contadores, agrupadas por competências ligadas à natureza contábil, empresarial ou profissional (AICPA, 2018).

Caminhando na mesma direção, o International Education Standard (IES) 3 destaca as habilidades que devem ser desenvolvidas pelo profissional contábil, agrupadas nas seguintes categorias (IFAC, 2010):

a) habilidade intelectuais: contribuem para solucionar problemas, tomar decisões e julgar situações complexas, assim como está relacionada ao conhecimento e entendimento cognitivo;

b) habilidades técnicas e funcionais: compreendem as habilidades gerais e específicas de contabilidade, assim como a matemática, estatística e conhecimento em tecnologia da informação

c) habilidades pessoais: compreendem as atitudes e comportamentos do profissional contábil que proporcionam melhoria na sua aprendizagem pessoal e profissional, assim como o comportamento ético e o autoaprendizado.

d) habilidades interpessoais e de comunicação: permitem que o profissional interaja com outras áreas de conhecimento, trabalhe em equipe, receba e transmita informações, forme julgamentos e tome decisões; e,

e) habilidades de gestão organizacional e de negócios: relacionadas ao funcionamento da organização, planejamento estratégico e gestão de processo.

Verifica-se então que na visão do IFAC (2010), há cinco categorias de habilidades profissionais: (i) habilidades intelectuais; (ii) habilidades técnicas e funcionais; (iii) habilidades pessoais; (iv) habilidades interpessoais e de comunicação; e, (v) habilidades de gestão organizacional e de negócios.

Pesquisas nacionais e internacionais verificaram a percepção de estudantes sobre o profissional contábil, demonstrando a relevância da compreensão do perfil das habilidades e competências desse profissional.

Leal et al. (2014) realizaram uma pesquisa com estudantes de ciências contábeis e com o público externo para identificar a existência de estereotipagem negativa do profissional contábil. Os autores não identificaram estereotipagem 
negativa em relação às variáveis: criatividade, dedicação aos estudos, trabalho em equipe, comunicação, liderança, propensão ao risco e ética. Além disso, observaram que, na compreensão do público externo, os profissionais de contabilidade são mais percebidos como sendo do gênero masculino.

Em contrapartida, Splitter e Borba (2014) analisaram a percepção da imagem da atividade profissional do contador pelos estudantes e professores de cinco cursos de graduação nas áreas de Contabilidade, Administração, Direito, Jornalismo e Engenharia de Produção de duas universidades de Santa Catarina. Os achados revelaram que a profissão contábil foi considerada uma carreira desinteressante, envolvendo atividades repetitivas, que cumpre normas e envolve muitos cálculos, além do que o próprio profissional vem sendo visto como introspectivo, pouco crítico e comunicativo. Quanto à profissão em si, percebeu-se predominância de aspectos quantitativos, bem como fiscais e tributários, principalmente relacionados à Declaração do Imposto de Renda.

Reis et al. (2015) identificaram e analisaram, a partir da percepção dos discentes do curso de ciências contábeis de uma IES situada em Minas Gerais, as principais construções sociais que os estudantes possuem em relação ao profissional contábil. Os autores utilizaram a técnica de evocação de palavras e aplicação de uma escala tipo Likert contemplando quatro dimensões correspondentes às competências e habilidades do profissional contábil: "Habilidades e Competências Técnicas e Funcionais", "Habilidades e Competências Pessoais", "Habilidades Intelectuais e do Conhecimento" e "Habilidades e Competências Organizacionais e Relação Interpessoal”.

A representação social que os discentes formaram do profissional contábil foi de um profissional de comportamentos e condutas éticas, com amplos conhecimentos teóricos e práticos, responsabilidade nas suas ações e comprometimento com o seu trabalho. As habilidades e competências percebidas como as mais importantes foram habilidades intelectuais e do conhecimento, assim como habilidades pessoais. Os autores complementam que esse resultado pode estar relacionado à forma curricular que o curso se estrutura (Reis et al. 2015).

Raffaelli, Espejo e Portulhak (2016) averiguaram a imagem social construída do profissional contábil por graduandos em ciências econômicas de uma IES pública sediada na região sul do Brasil. De forma geral, constatou-se que os futuros economistas depositam confiança nos contabilistas, além de reconhecer a importância e complexidade do trabalho desses profissionais. No entanto, devido ao entendimento de que a contabilidade está atrelada à legislação tributária, prevalece a noção de que os atuantes no campo contábil são desprovidos de criatividade e de visão holística. Os autores argumentam que é importante transmitir uma imagem positiva do profissional contábil, para reduzir possíveis efeitos negativos de determinadas percepções que diminuam a atividade contábil.

Galvão (2016) verificou como estudantes do ensino médio, prestes a escolherem o curso universitário, percebem o profissional contábil, em meio a fatores que podem ou não influenciar nesse processo decisório, como família, fatores sociais e psicológicos. Os resultados apontaram que os entrevistados entendem que o contador realiza atividades como cálculos dos impostos, análise de custos, elaboração de folha de pagamento e declaração do imposto de renda. Ademais, 79,46\% dos respondentes consideram o contador importante para o desenvolvimento do país, bem como 63,39\% dos estudantes entendem que o profissional da área contábil é capaz de ajudar o governo a aplicar bem os impostos, ao mesmo tempo em que 47,32\% dos estudantes apontaram que o contador pode ajudar a diminuir a corrupção no país.

Almeida e Medeiros (2017) procuraram compreender como o contador atualmente é percebido pelos discentes de ciências contábeis, decorridos 10 anos da criação do Sistema Público de Escrituração Digital (SPED) e da Lei no 11.638/2007. Os autores avaliaram se havia diferentes percepções entre ingressantes e concluintes. Os resultados revelaram que a ética, responsabilidade e honestidade foram mais expressivos entre os participantes da pesquisa. Contudo, alguns ingressantes entrevistados descreveram a figura do profissional contábil como calculador de tributos.

Tan e Laswad (2018) examinaram as habilidades de empregabilidade dos contadores citados em anúncios de emprego 
na Austrália e na Nova Zelândia. Os resultados indicam que as habilidades interpessoais e pessoais são as habilidades mais frequentemente solicitadas. Foram identificadas 31 habilidades, destacando-se a capacidade de colaborar com colegas, discutir e defender pontos de vista e ter uma atitude positiva. Tal fato reflete a mudança no trabalho de contadores, deixando de ser "analistas de bastidores" para serem profissionais de negócios engajados. Desse modo, os autores reforçam a importância de incorporar o desenvolvimento de tais habilidades no currículo dos cursos de contabilidade.

Asonitou e Hassall (2019) investigaram a incorporação de habilidades profissionais no ensino de contabilidade grego. Os resultados identificaram a necessidade de desenvolver as habilidades de pensamento crítico de contadores em potencial por meio de novas abordagens de ensino e do desenvolvimento de um currículo que apoia empregabilidade e desenvolvimento sustentável dos graduados. Tais achados corroboram com o estudo de Douglas e Gammie (2019), que destacam a necessidade de habilidades não técnicas para o profissional contador da atualidade que opera em um ambiente sociotécnico dinâmico.

\section{Procedimentos Metodológicos}

A presente pesquisa caracteriza-se como descritiva e quantitativa, utilizando o questionário como instrumento de coleta de dados. Os questionários foram aplicados presencialmente com os estudantes dos cursos de administração e ciências contábeis de uma universidade pública localizada no interior do Estado do Ceará, nos meses de outubro e novembro de 2019. Ao todo, foram validados 237 questionários.

O referido instrumento foi baseado no estudo de Reis et al. (2015) e foi dividido em três etapas. A primeira etapa contemplava o perfil dos respondentes, com questões sobre curso, gênero, idade, semestre e turno. Na segunda parte, o discente deveria evidenciar a quantidade máxima de palavras que vinham a sua mente quando vissem a expressão "habilidades e competências necessárias para atuação do profissional contábill". Esse método é conhecido como evocação de palavras, que, segundo Vergara (2005), representa uma forma de coleta de dados que instiga os indivíduos pesquisados a mencionarem, oralmente ou por escrito, palavras que lhe vem à cabeça, a partir da evocação pelo pesquisador de uma expressão indutora.

$\mathrm{Na}$ terceira parte do questionário, foram construídas 19 afirmações, do tipo escala Likert, que permitiram medir as percepções e o grau de conformidade do entrevistado com qualquer afirmação proposta (Llauradó, 2015). Os estudantes deveriam informar o nível de importância para cada afirmativa sobre as competências e habilidades do profissional contábil. O nível de importância variava de 1 a 5, sendo: 1 para "não é importante"; 2 para "pouco importante"; 3 para "importante"; 4 para "muito importante"; e 5 para "indispensável".

Destaca-se que essas afirmativas correspondem a 18 características do profissional contábil, em que cada caraterística pertence a uma dimensão. No Quadro 1, são evidenciadas essas características com suas respectivas dimensões. 
Quadro 1. Dimensões e características das habilidades e competências do profissional contábil.

\begin{tabular}{|c|c|}
\hline Dimensão & Descrição das características \\
\hline \multirow{4}{*}{$\begin{array}{c}\text { Habilidades e } \\
\text { Competências Técnicas e } \\
\text { Funcionais }\end{array}$} & $\begin{array}{c}\text { Habilidades gerais e específicas da contabilidade, como as competências técnicas (análise de } \\
\text { risco, mensuração, relatórios). }\end{array}$ \\
\hline & Terminologia contábil e o domínio contábil. \\
\hline & Noções atuárias e terminologia atuária. \\
\hline & Desenvolver informação, analisar informação e implantar informação. \\
\hline \multirow{3}{*}{$\begin{array}{l}\text { Habilidades e } \\
\text { Competências Pessoais }\end{array}$} & $\begin{array}{c}\text { Comportamentos e atitudes do profissional contábil que proporcionam melhoria no } \\
\text { relacionamento profissional. }\end{array}$ \\
\hline & $\begin{array}{c}\text { Comportamentos e atitudes do profissional contábil que proporcionam melhoria no } \\
\text { aprendizado individual. }\end{array}$ \\
\hline & Ética e práticas na comunidade. \\
\hline \multirow{5}{*}{$\begin{array}{l}\text { Habilidades Intelectuais e } \\
\text { do Conhecimento }\end{array}$} & Atribuições para solucionar problemas, tomar decisões e julgar situações complexas. \\
\hline & $\begin{array}{l}\text { Conhecimentos em contabilidade e áreas afins (contabilidade financeira, gerencial, auditoria } \\
\text { entre outros) e relacionados aos negócios. }\end{array}$ \\
\hline & Visão sistêmica, conhecimento econômico e visão crítica e analítica. \\
\hline & Conhecimentos de legislação, informações patrimoniais e legislações específicas. \\
\hline & Conhecimentos em normas internacionais e questões científicas. \\
\hline \multirow{6}{*}{$\begin{array}{c}\text { Habilidades e } \\
\text { Competências } \\
\text { Organizacionais e Relação } \\
\text { Interpessoal }\end{array}$} & Entendimento do ambiente interno e externo dos negócios. \\
\hline & Habilidades relacionadas ao funcionamento da organização. \\
\hline & Interação com outras áreas de conhecimento. \\
\hline & Receber e transmitir informações, formar julgamentos e tomar decisões. \\
\hline & Gerenciamento, tomada de decisão, construção de valores, modelos organizacionais. \\
\hline & Entendimento de organizações públicas, organizações privadas e terceiro setor. \\
\hline
\end{tabular}

Fonte: Adaptado de Reis et al. (2015).

Observa-se que ao todo foram consideradas quatro dimensões, correspondentes às competências e habilidades do profissional contábil: "Habilidades e Competências Técnicas e Funcionais", "Habilidades e Competências Pessoais", "Habilidades Intelectuais e do Conhecimento" e "Habilidades e Competências Organizacionais e Relação Interpessoal".

Cumpre mencionar que na segunda parte do questionário (método de evocação de palavras), foi calculada a frequência de cada palavra evocada e em seguida foram alocadas com base nas quatro dimensões das competências e habilidades do profissional contábil.

No que tange à análise dos dados, inicialmente, realizou-se análise descritiva, seguida da análise por meio do método de evocação de palavras. Além disso, calculou-se o Alfa de Cronbach, com a finalidade de verificar a confiabilidade dos dados. Por fim, recorreu-se ao Teste de Mann-Whitney para verificar se havia diferença estatística entre as respostas dos grupos de respondentes. Optou-se pelo teste Mann-Whitney pois os dados apresentaram distribuição não normal.

\section{Resultados}

\subsection{Perfil dos respondentes}

As características dos respondentes são evidenciadas na Tabela 1, segmentada pela sua frequência e percentual para melhor avaliação das categorias. 
Tabela 1. Perfil dos respondentes.

\begin{tabular}{|c|c|c|c|}
\hline Categoria & Classificação & Frequência & Percentual \\
\hline \multirow{2}{*}{ Curso } & Administração & 119 & $50,21 \%$ \\
\hline & Ciências Contábeis & 118 & $49,79 \%$ \\
\hline \multirow{2}{*}{ Gênero } & Feminino & 110 & $46,41 \%$ \\
\hline & Masculino & 127 & $53,59 \%$ \\
\hline \multirow{2}{*}{ Faixa Etária } & Até 20 anos & 96 & $40,51 \%$ \\
\hline & 21 anos ou mais & 141 & $59,49 \%$ \\
\hline \multirow{2}{*}{ Semestre } & Até $4^{\circ}$ semestre & 118 & $49,79 \%$ \\
\hline & $5^{\circ}$ semestre ou mais & 119 & $50,21 \%$ \\
\hline \multirow{2}{*}{ Turno } & Diurno & 60 & $25,32 \%$ \\
\hline & Noturno & 177 & $74,68 \%$ \\
\hline Total de respondentes & & 237 & $100,00 \%$ \\
\hline
\end{tabular}

Fonte: Dados da pesquisa.

A partir da Tabela 1, percebe-se um equilíbrio na quantidade de alunos matriculados nos cursos de administração e ciências contábeis, bem como entre alunos dos semestres iniciais (até o $4^{\circ}$ semestre) e dos semestres finais $\left(5^{\circ}\right.$ semestre ou mais). Em contrapartida, houve predominância de alunos do gênero masculino (53,59\%), com 21 anos ou mais (59,49\%) e de turno noturno $(74,68 \%)$.

\subsection{Método da evocação das palavras}

Segue disposta na Tabela 2 a distribuição das palavras mencionadas pelos estudantes do curso de administração e ciências contábeis.

Tabela 2. Palavras mencionadas pelos estudantes.

\begin{tabular}{|c|c|c|c|}
\hline Dimensão & Administração & Ciências Contábeis & Total \\
\hline $\begin{array}{c}\text { Habilidades e } \\
\text { Competências } \\
\text { Técnicas e Funcionais }\end{array}$ & $\begin{array}{l}\text { Lançamentos (9), analista (6), controle } \\
\text { (3), relatórios e documentos (3) }\end{array}$ & $\begin{array}{c}\text { Analista (6), avaliador (2), evidenciar (2), } \\
\text { organizado (2), soluções (2), lançamentos (1), } \\
\text { consultor (1) }\end{array}$ & 37 \\
\hline $\begin{array}{l}\text { Habilidades e } \\
\text { Competências } \\
\quad \text { Pessoais }\end{array}$ & $\begin{array}{l}\text { Ética (6), honestidade (2), liderança } \\
\text { (2), atenção (1) atualizado (1), } \\
\text { competência (1), comunicação (1), } \\
\text { cumplicidade (1), disciplina (1), } \\
\text { imparcialidade (1), proativo (1), } \\
\text { profissional (1), saber interpretar (1) }\end{array}$ & $\begin{array}{l}\text { Ética (7), atualizado (4) comunicativo (3), } \\
\text { aprendiz (2), credibilidade (2), flexível (2), } \\
\text { habilidades pessoais (2), responsabilidade (2), } \\
\text { valores (2), credibilidade (1), atenção (1), } \\
\text { compreensão (1), didática (1), dinâmico (1), } \\
\text { esperto (1), íntegro (1), liderança (1), moral } \\
\text { (1), postura (1), proativos (1), qualificado (1), } \\
\text { ter iniciativa (1) }\end{array}$ & 59 \\
\hline $\begin{array}{l}\text { Habilidades } \\
\text { Intelectuais e do } \\
\text { Conhecimento }\end{array}$ & $\begin{array}{l}\text { Cálculos (40), contas (7), patrimônio } \\
\text { (4), balanços (3), conhecimento fiscal } \\
\text { (2), estatística (2), finanças (2), custos } \\
\text { (1), débito (1), demonstrações (1), } \\
\text { economia (1), números (1) }\end{array}$ & $\begin{array}{l}\text { Informatizado (10), conhecimentos diversos } \\
\text { (9), conhecimento contábil (3), conhecimento } \\
\text { técnico (2), finanças (2), habilidade com } \\
\text { dados (2), matemática (2), cálculos (1), } \\
\text { conhecimento fiscal (1), CPCs (1), números } \\
\text { (1), patrimônio (1), sistemas (1) }\end{array}$ & 101 \\
\hline $\begin{array}{c}\text { Habilidades e } \\
\text { Competências } \\
\text { Organizacionais e } \\
\text { Relação Interpessoal } \\
\end{array}$ & $\begin{array}{c}\text { Negócios (3) mercado financeiro (2) } \\
\text { abertura de negócios (1), informações } \\
\text { (1), soluções (1), tomada de decisão } \\
\text { (1), visão ampla (1) }\end{array}$ & $\begin{array}{c}\text { Informações (4), interpessoal (4), ouvinte (3), } \\
\text { estratégico (2), negócios (2) }\end{array}$ & 25 \\
\hline Total & 116 & 106 & 222 \\
\hline
\end{tabular}

Fonte: Dados da pesquisa.

Como se observa na Tabela 2, o curso com a maior quantidade de palavras mencionadas foi o da administração, com 116 palavras indicadas, enquanto o curso de ciências contábeis evocou apenas 106 palavras. Em relação às competências para 
cada curso, observou-se que, para os alunos do curso de administração, há maior destaque para as "Habilidades Intelectuais e do Conhecimento" em que a palavra mais mencionada foi "cálculos". Em vista disso, percebe-se que, para esses estudantes, a principal habilidade para o exercício do profissional contábil está relacionada a cálculos, o que converge com os resultados de Raffaelli et al. (2016), que verificaram que habilidades relacionadas a cálculos foi representativa entre os alunos de ciências econômicas. Além disso, no estudo de Schlee et al. (2007), observou-se um consenso entre os estudantes da área de gestão, que percebem que os alunos que optam por se especializar em contabilidade apresentam melhores habilidades em matemática.

Além da palavra "cálculos", destacam-se palavras como "lançamentos", "contas", "balanços", "ética" e "patrimônio". Com base nisso, compreende-se que os estudantes de administração parecem ter uma visão tradicionalista sobre o profissional contábil, dando ênfase a aspectos operacionais de escrituração contábil. De acordo com Splitter e Borba (2014), o profissional contábil costuma ser associado a conhecimentos envolvendo cálculos e matemática, além de questões ligadas a aspectos fiscais e tributários, corroborando os achados desta pesquisa. Desse modo, observa-se que a visão sobre este profissional não mudou nos últimos tempos, evidenciando a urgência de uma reflexão sobre o papel do contabilista no âmbito empresarial e social, levando a sociedade a compreender melhor sobre as habilidades e competências necessárias para o exercício da atividade contábil.

No que compete ao curso de ciências contábeis, as palavras mais expressadas estavam relacionadas às "Habilidades e Competências Pessoais". Desse modo, compreende-se que os estudantes de ciências contábeis apresentam uma visão mais orientada a aspectos comportamentais do profissional contábil, atribuindo aspectos como "ética", "comunicação", "flexibilidade", entre outros. Nesse contexto, Schlee et al. (2007) verificaram que os estudantes de contabilidade se descrevem como pessoas de boa comunicação e liderança, ambiciosas, organizadas, com domínio matemático, flexíveis, independentes e que sabem trabalhar em equipe. Assim, pode-se dizer que há alinhamento entre as percepções dos estudantes de ciências contábeis investigados nesta pesquisa e aquelas apontadas pelos estudantes na pesquisa de Schlee et al. (2007). Além disso, a palavra "informatizado", categorizada na dimensão "Habilidades Intelectuais e do Conhecimento", apresentou maior número de repetições, evidenciando que o contador deve estar atualizado com as mudanças tecnológicas.

Analisando conjuntamente os dois cursos, verifica-se que as palavras mais lembradas foram relativas às "habilidades intelectuais e do conhecimento", com o total de 101 palavras. As habilidades menos importantes foram relacionadas às "habilidades e competências organizacionais e relação interpessoal", com apenas 25 palavras. Tal fato corrobora os achados de Schlee et al. (2007), em que as características menos atribuídas à contabilidade pelos estudantes da área de gestão (i.e. contabilidade, economia, administração, marketing, finanças, gestão da informação e negócios internacionais) estavam relacionadas à criatividade e a assumir riscos.

Além disso, embora os estudantes de contabilidade considerem que contam com boas habilidades interpessoais, os estudantes de outras áreas de negócios parecem considerar que os estudantes de contabilidade não são orientados às pessoas, são pouco flexíveis e carecem de boa comunicação e liderança (Schlee et al., 2007). Por fim, verificou-se que as palavras em comum aos estudantes dos dois cursos foram: "analista/analítico", "ético", "proativo", "comunicativo/comunicação", "atualizado", "cálculos", "negócios", "finanças" e "patrimônio". Portanto, essas palavras estabelecem a representação comum entre os discentes das competências e habilidades do profissional contábil.

\subsection{Percepções das competências e habilidades do profissional contábil em relação ao perfil do respondente}

Inicialmente, calculou-se o Alfa de Cronbach, a fim de verificar a confiabilidade dos dados. A Tabela 3 apresenta as dimensões das competências e habilidades do profissional contábil que são analisadas nesta pesquisa. 
Tabela 3. Alfa de Cronbrach das dimensões.

\begin{tabular}{lc}
\hline Dimensão & Alfa de Cronbach \\
\hline Habilidades e Competências Técnicas e Funcionais & 0,502 \\
Habilidades e Competências Pessoais & 0,697 \\
Habilidades Intelectuais e do Conhecimento & 0,735 \\
Habilidades e Competências Organizacionais e Relação Interpessoal & 0,948 \\
\hline
\end{tabular}

Fonte: Dados da pesquisa.

Na Tabela 3, verifica-se que todas as dimensões "habilidades e competências pessoais", "habilidades intelectuais e do conhecimento" e "habilidades e competências organizacionais e relação interpessoal" apresentaram valores do Alfa de Cronbach superiores a 0,6. De acordo com Hair Jr. et al. (2009), valores superiores a 0,6 são considerados aceitáveis e indicam consistência interna dos dados. A dimensão "habilidades e competências técnicas e funcionais" apresentou Alfa de Cronbach inferior a 0,6, mas superior a 0,5. Embora sejam baixos, valores superiores a 0,5 podem ser considerados aceitáveis (George \& Mallery, 2003). Portanto, de modo geral, os dados indicam consistência na avaliação. Dessa forma, optou-se por utilizar a média de cada dimensão relacionada às competências e habilidades do profissional contábil como variável a ser comparada entre os grupos de estudantes com base nas características do perfil dos respondentes.

Tabela 4. Percepções das competências e habilidades do profissional contábil em relação ao curso.

\begin{tabular}{lccc}
\hline & Administração & C. Contábeis & Mann-Whitney \\
\hline Dimensão & $\mathbf{N = 1 1 9}$ & $\mathbf{N = 1 1 8}$ & Valor-p \\
\hline Hab. e Comp. Técnicas e Funcionais & 4,027 & 4,464 & $<0,001^{* * *}$ \\
Hab. e Comp. Pessoais & 4,860 & 4,375 & $<0,001^{* * *}$ \\
Hab. Intelectuais e do Conhecimento & 3,123 & 4,285 & $<0,001^{* * *}$ \\
Hab. e Comp. Organizacionais e Relação Interpessoal & 1,931 & 3,816 & $<0,001^{* * *}$ \\
\hline
\end{tabular}

Nota: ${ }^{* * *}$ Significante ao nível de $1 \%$ (valor-p < 0,01); ${ }^{* *}$ Significante ao nível de 5\% (valor-p < 0,05). Fonte: Dados da pesquisa.

De acordo com a Tabela 4, todas dimensões apresentaram diferença estatística significante (valor-p < 0,01) em relação ao curso. Portanto, verificou-se que os estudantes do curso de ciências contábeis e de administração têm percepções diferentes em relação às habilidades e competências do profissional contábil. Destaca-se que os estudantes de contabilidade tendem a atribuir maior importância às questões relacionadas a "habilidades e competências técnicas e funcionais", "habilidades intelectuais e do conhecimento" e "habilidades e competências organizacionais e relação interpessoal", enquanto os estudantes de administração atribuem maior importância às "habilidades e competências pessoais".

Destaca-se que os estudantes de administração atribuíram baixa importância para as "habilidades e competências organizacionais e relação interpessoal", que envolvem itens relacionados ao "entendimento do ambiente interno e externo dos negócios", ao "funcionamento da organização", "interação com outras áreas de conhecimento", "informações, julgamentos e tomada decisões", entre outros. Isso denota que os estudantes de administração compreendem que habilidades mais gerenciais não são tão relevantes para a prática contábil, o que pode estar associada a uma visão estereotipada sobre a profissão. De modo geral, é esperado que os estudantes de contabilidade atribuam maior importância às habilidades e competências do profissional contábil, uma vez que possuem maior identificação e familiaridade com a profissão. 
Tabela 5. Percepções das competências e habilidades do profissional contábil em relação ao gênero.

\begin{tabular}{lccc}
\hline & Feminino & Masculino & Mann-Whitney \\
\hline Dimensão & N =110 & N = 127 & Valor-p \\
\hline Hab. e Comp. Técnicas e Funcionais & 4,196 & 4,287 & 0,098 \\
Hab. e Comp. Pessoais & 4,721 & 4,530 & $<0,001^{* * * *}$ \\
Hab. Intelectuais e do Conhecimento & 3,620 & 3,772 & $0,033^{* *}$ \\
Hab. e Comp. Organizacionais e Relação Interpessoal & 2,818 & 2,914 & 0,318 \\
\hline
\end{tabular}

Nota: ${ }^{* * *}$ Significante ao nível de $1 \%$ (valor-p < 0,01); ${ }^{* *}$ Significante ao nível de 5\% (valor-p < 0,05). Fonte: Dados da pesquisa.

Em relação gênero dos respondentes, os resultados evidenciados na Tabela 5 indicam que as mulheres atribuem maior importância às "habilidades e competências pessoais" do que os homens (valor-p < 0,01), enquanto os homens atribuem maior importância para as "habilidade e competências intelectuais e do conhecimento" do que as mulheres (valor-p < 0,05). Desse modo, compreende-se que, enquanto os homens priorizam aspectos como solucionar problemas, conhecimentos contábeis (i.e. contabilidade financeira, gerencial, auditoria, etc) legislação e normas, as mulheres prezam por aspectos como aprendizado, relacionamento e ética. Em relação as demais dimensões, não foi verificada diferença estatística entre as percepções de homens e mulheres.

Nesse contexto, o estudo de Shtudiner e Klein (2020) evidenciou que mulheres são menos tolerantes em relação a comportamentos antiéticos, sugerindo que as mulheres priorizam aspectos que proporcionam melhoria na aprendizagem individual e ações éticas. Alinhado a isto, Lucas e Santos (2019) verificaram que as mulheres atribuem maior importância à ética na profissão contábil que os homens. Já no estudo de Mbawuni (2015), no que se refere aos estudantes de graduação, não foram verificadas diferenças nas percepções de homens e mulheres em relação: à reputação percebida do profissional contábil; aos resultados do trabalho contábil; ao sentimento em relação à profissão contábil; e aos requisitos para o trabalho contábil. No entanto, o autor verificou que as alunas de graduação em contabilidade têm uma percepção mais negativa em relação aos comportamentos do profissional contábil.

Tabela 6. Percepções das competências e habilidades do profissional contábil em relação à idade.

\begin{tabular}{lccc}
\hline & Até 20 anos & 21 ou mais & Mann-Whitney \\
\hline Dimensão & $\mathbf{N = 9 6}$ & $\mathbf{N = 1 4 1}$ & Valor-p \\
\hline Hab. e Comp. Técnicas e Funcionais & 4,177 & 4,291 & $0,004^{* * *}$ \\
Hab. e Comp. Pessoais & 4,764 & 4,520 & $<0,001^{* * *}$ \\
Hab. Intelectuais e do Conhecimento & 3,710 & 3,695 & 0,638 \\
Hab. e Comp. Organizacionais e Relação Interpessoal & 2,724 & 2,969 & 0,080 \\
\hline
\end{tabular}

Nota: ${ }^{* * *}$ Significante ao nível de $1 \%$ (valor-p < 0,01); ${ }^{* *}$ Significante ao nível de 5\% (valor-p < 0,05). Fonte: Dados da pesquisa.

No que se refere à idade dos respondentes, verificou-se, com base na Tabela 6, que os estudantes mais velhos atribuem maior importância às "habilidades e competências técnicas e funcionais" (valor-p < 0,01). Por outro lado, os estudantes mais jovens atribuem maior importância às "habilidades e competências pessoais" (valor-p < 0,01). Desse modo, compreende-se que os mais jovens (até 20 anos) tendem a priorizar aspectos como aprendizagem, relacionamento e ética, enquanto os mais velhos (21 anos ou mais) dão maior importância a aspectos mais técnicos e funcionais da prática contábil. No estudo de Lucas e Santos (2019), os autores não encontraram diferenças em relação à idade dos respondentes no que se refere às percepções sobre o comportamento ético do profissional de contabilidade. 
Tabela 7. Percepções das competências e habilidades do profissional contábil em relação ao semestre.

\begin{tabular}{lccc}
\hline & Até o 4$^{\mathbf{0}}$ & $\mathbf{5}^{\mathbf{0}}$ ou mais & Mann-Whitney \\
\hline Dimensão & $\mathbf{N = 1 1 8}$ & $\mathbf{N = \mathbf { 1 1 9 }}$ & Valor-p \\
\hline Hab. e Comp. Técnicas e Funcionais & 4,201 & 4,288 & $0,027^{* *}$ \\
Hab. e Comp. Pessoais & 4,728 & 4,510 & $<0,001^{* * * *}$ \\
Hab. Intelectuais e do Conhecimento & 3,737 & 3,665 & 0,202 \\
Hab. e Comp. Organizacionais e Relação Interpessoal & 2,799 & 2,939 & 0,418 \\
\hline
\end{tabular}

Nota: ${ }^{* * *}$ Significante ao nível de $1 \%$ (valor-p < 0,01); ${ }^{* *}$ Significante ao nível de 5\% (valor-p < 0,05). Fonte: Dados da pesquisa.

De acordo com a Tabela 7, observou-se que os estudantes dos semestres finais atribuem maior importância às "habilidades e competências técnicas e funcionais" quando comparados aos estudantes dos semestres iniciais (valor-p < 0,05). Em contrapartida, verificou-se que os estudantes dos semestres iniciais atribuem maior importância às "habilidades e competências pessoais" do que os estudantes dos semestres finais (valor-p < 0,01). Estes achados divergem daqueles encontrados por Reis et al. (2015). Além disso, Almeida e Medeiros (2017) verificaram que alguns estudantes ingressantes descreveram a figura de um contador "calculador de tributos", uma habilidade que pode ser considerada mais funcional, enquanto nenhum concluinte das instituições de ensino participantes mencionou essa percepção.

Tabela 8. Percepções das competências e habilidades do profissional contábil em relação ao turno.

\begin{tabular}{lccc}
\hline & Diurno & Noturno & Mann-Whitney \\
\hline Dimensão & $\mathbf{N = 6 0}$ & $\mathbf{N}=\mathbf{1 7 7}$ & Valor-p \\
\hline Hab. e Comp. Técnicas e Funcionais & 4,404 & 4,191 & $<0,001^{* * *}$ \\
Hab. e Comp. Pessoais & 4,543 & 4,644 & 0,062 \\
Hab. Intelectuais e do Conhecimento & 4,340 & 3,485 & $<0,001^{* * *}$ \\
Hab. e Comp. Organizacionais e Relação Interpessoal & 3,550 & 2,639 & $<0,001^{* * *}$ \\
\hline
\end{tabular}

Nota: ${ }^{* * *}$ Significante ao nível de $1 \%$ (valor-p < 0,01); ${ }^{* *}$ Significante ao nível de 5\% (valor-p < 0,05). Fonte: Dados da pesquisa.

Verificou-se, de acordo com a Tabela 8, que os estudantes do turno diurno atribuem maior importância às "habilidades e competências técnicas e funcionais" (valor-p < 0,01) e "habilidades e competências organizacionais e relação interpessoal" (valor-p < 0,01) quando comparados com os alunos do turno noturno. Por outro lado, os alunos do turno noturno atribuem maior importância às "habilidades e competências pessoais" (valor-p < 0,01) do que os alunos do turno diurno. Estes achados sugerem que há diferença entre as percepções dos estudantes de diferentes turnos em uma mesma IES.

\section{Considerações Finais}

O objetivo dessa pesquisa foi analisar a percepção dos discentes dos cursos de administração e ciências contábeis de uma universidade estadual sobre as competências e habilidades do profissional contábil. Para tanto, desenvolveu-se uma pesquisa quantitativa, em que foram aplicados questionários com 237 estudantes da instituição. O questionário foi elaborado com base no estudo de Reis et al. (2015). Em relação ao perfil do respondente, houve equilíbrio na quantidade de alunos dos cursos de administração e ciências contábeis, bem como entre alunos iniciantes (até o $4^{\circ}$ semestre) e os concludentes $\left(5^{\circ}\right.$ semestre ou mais). Em contrapartida, houve maior quantidade de alunos do gênero masculino (53,59\%), mais velhos (21 anos ou mais) e que estudam no turno noturno $(74,68 \%)$.

De forma geral, verificou-se diferentes perspectivas existentes entre os estudantes no que se refere às competências e habilidades do profissional contábil. Enquanto os estudantes de administração parecem ter uma visão mais restrita sobre a atuação do profissional contábil, os estudantes de ciências contábeis parecem ter uma visão mais abrangente. Isso leva à compreensão de que, de forma geral, ainda há uma visão estereotipada sobre o profissional contábil por parte daquele que não tem um contato direto com a profissão. Além disso, observou-se que há diferentes percepções entre os estudantes a depender 
do gênero, faixa etária, turno e etapa do curso. Desse modo, o estudo contribui para fomentar a discussão sobre as competências do profissional contábil entre estudantes de administração e ciências contábeis.

Para trabalhos futuros, sugere-se verificar a percepção de estudantes de outras IES, bem como as percepções de profissionais da área de gestão (contadores, administradores, economistas, etc). Além disso, sugere-se o emprego de outras abordagens, técnicas e métodos de pesquisa, tais como entrevistas e grupos focais, a fim de explorar o fenômeno através de outras lentes. Por fim, como limitações da pesquisa, destaca-se que os resultados aqui apresentados não podem ser extrapolados para outras realidades, tendo em vista que apenas uma IES foi analisada.

\section{Referências}

Almeida, G. T., \& Medeiros, L. M. (2017). Percepção em relação ao profissional contábil: investigação comparativa com estudantes, ingressantes e concluintes. Revista de Contabilidade do Mestrado em Ciências Contábeis da UERJ, 22(1), 104-121.

American Institute of Certified Public Accountants - AICPA. (2018). Pre-certification Core Competency Framework. New York: AICPA. Recuperado em 21 dezembro, 2019, de http://www.aicpa.org/.

Amorim, J. E. B. A. (2017). A "Indústria 4.0" e a sustentabilidade do modelo de financiamento do regime geral da segurança social. Cadernos de Dereito Actual, Santiago de Compostela, (5), 243-254.

Araújo, M. D. C., \& Santana, C. M. (2008, July). Análise das percepções e expectativas dos alunos de ciências contábeis na universidade de Brasília quanto ao perfil do professor e inserção no mercado de trabalho. Anais do Congresso USP de Contabilidade e Controladoria, São Paulo, SP, Brasil, 21.

Asonitou, S., \& Hassall, T. (2019). Quais habilidades e competências desenvolver nos contadores em um país em crise?. The International Journal of Management Education, 17(3), 100308.

Barrie, C. S. (2012). A research-based approach to generic graduate attributes policy. Higher Education Research and Development, 31(1), 79-92.

Borges, G., \& Naves, F. (2014). Ensino de contabilidade na graduação em administração: uma análise sob a perspectiva discente. Revista de Contabilidade $e$ Organizações, $8(21), 58-70$.

Borges, G., \& Mafra, F. L. N. (2013). Ensino de contabilidade em cursos de graduação em administração: uma análise da percepção docente e discente em instituições de ensino superior de Minas Gerais. RACE: Revista de Administração, Contabilidade e Economia, 12(3), 191-226.

Cardoso, R. L., Riccio, E. L., \& Albuquerque, L. G. (2009). Competências do contador: um estudo sobre a existência de uma estrutura de interdependência. Revista de Administração da Universidade de São Paulo, 44(4), 365-379.

Cardoso, R. L., Riccio, E. L., Mendonça Neto, O. R., \& Oyadomari, J. C. (2010). Entendendo e explorando as competências do contador gerencial: uma análise feita pelos profissionais. ASAA-Advances in Scientific and Applied Accounting, 3(3), 353-371.

Cunha, J. V. A., De Luca, M. M. M., Lima, G. A. S. F., Cornacchione Jr, E. B., \& Ott, E. (2015). Quem está ficando para trás? Uma década de evasão nos cursos brasileiros de graduação em Administração de Empresas e Ciências Contábeis. Revista de Educação e Pesquisa em Contabilidade, 9(2), $124-142$.

Dani, A. C., Santos, C. A., Cecon, B., Silva, T. B. de J., \& Hein, N. (2017). Tendência empreendedora nos discentes dos cursos de administração e ciências contábeis de uma instituição de ensino superior. Revista Mineira de Contabilidade, 18(2), 54-69.

Department of Education, Employment and Workplace Relations (DEEWR). (2012). Employability skills framework Stage 1 - Final Report. Canberra: Australian Government Printing Service.

Douglas, S., \& Gammie, E. (2019). An investigation into the development of non-technical skills by undergraduate accounting programmes. Accounting Education, 28(3), 304-332.

Galvão, N. M. S. (2016). Percepção dos estudantes do ensino médio acerca do profissional contábil. Revista Evidenciação Contábil \& Finanças, 4(2), $40-53$.

George, D., \& Mallery, P. (2003) SPSS for Windows step by step: a simple guide and reference (4a ed.). Boston: Allyn \& Bacon.

Gomes, D. M. (2003). Competências e habilidades do diretor. Campo Grande, MS: UCDB, 1.

Hair Jr., J. F., William, B., Babin, B., \& Anderson, R. E. (2009). Análise multivariada de dados (6a. ed.). Porto Alegre: Bookman.

Hunt, S. C., Falgiani, A. A., \& Intrieri, R. C. (2004). The nature and origins of students' perceptions of accountants. Journal of Education for Business, 79(3), 142-148.

Howieson, B. (2003). Accounting practice in the new millennium: is accounting education ready to meet the challenge? The British Accounting Review, 35, 69-103.

International Federation of Accountants - IFAC. Handbook of International Education Pronouncements. (2010). Edition. New York. Recuperado em 06 novembro, 2019, de https://www.ifac.org/system/files/publications/files/handbook-of-international-e-2.pdf. 
Leal, E. A., Miranda, G. J.; Araújo, T. S., \& Borges, L. F. M. (2014). Estereótipos na profissão contábil: a opinião de estudantes e do público externo no Triângulo Mineiro. Contabilidade, Gestão e Governança, 17(1), 134-153.

Lucas, A., \& Santos, L. L. (2019). Ethics in the accounting profession: a gender and age comparative study. SWS Journal of Social Sciences and Art, 1(1), 6777.

Llauradó, O. (2015). Escala Likert: o que é e como utilizá-la. Recuperado em 02 agosto, 2019, de https://www.netquest.com/blog/br/escala-likert.

Martins, J. V., Martins, Z. B., \& Morais, M. L. S. (2019). Atributos e habilidades do profissional contábil e a importância de seus serviços para a tomada de decisão empresarial. Revista Mineira de Contabilidade, 20(1), 5-18.

Mbawuni, J. (2015). Examining students' feelings and perceptions of accounting profession in a developing country: the role of gender and student category. International Education Studies, 8(6), 9-23.

Ott, E., Cunha, J. V. A., Cornachione Jr., E. B., \& De Luca, M. M. M. (2011). Relevância dos conhecimentos, habilidades e métodos instrucionais na perspectiva de estudantes e profissionais da área contábil: estudo comparativo internacional. Revista Contabilidade \& Finanças, 22(57), 338-356.

O’Connell, B., Carnegie, G. D., Carter, A. J., Hancock, P., Helliar, C. V., \& Watty, K. (2015). Shaping the future of accounting in business education in Australia. Melbourne: CPA Australia.

Raffaelli, S. C. D., Espejo, M. M. S. B., \& Portulhak, H. (2016). A imagem do profissional contábil: análise da percepção socialmente construída por estudantes de ciências econômicas. Revista Contemporânea de Contabilidade, 13(29), 157-178.

Reis, A. de O., Sediyama, G. A. S., Moreira, V. S., \& Moreira, C. C. (2015). Perfil do profissional contábil: habilidades, competências e imagem simbólica. Revista Contemporânea de Contabilidade, 12(25), 95-116.

Samsuri, A. S. B., Arifin, T. R. B. T., \& Hussin, S. B. (2016). Perception of undergraduate accounting students towards professional accounting career. International Journal of Academic Research in Accounting, Finance and Management Sciences, 6(3), 78-88.

Schlindwein, A. C. (2007). O ensino de ciências contábeis nas instituições de ensino da mesorregião do Vale do Itajaí/SC: uma análise das contribuições curriculares da Resolução CNE/CES N. 10/2004. Dissertação de mestrado, Universidade Regional de Blumenau, Blumenau, SC, Brasil.

Schlee, R., Curren, M., Harich, K., \& Kiesler, T. (2007). Perception bias among undergraduate business students by major. Journal of Education for Business, 82(3), 169-177.

Shtudiner, Z., \& Klein, G. (2020). Gender, attractiveness, and judgment of impropriety: the case of accountants. European Journal of Political Economy, 64, 101916.

Smith, D., \& Jacobs, K. (2011). Breaking up the sky: the characterisation of accounting and accountants in popular music. Accounting, Auditing \& Accountability Journal, 24(7), 904-931.

Soares, J. M. M. V., Souza, A. N. M. de, Azevedo, Y. G. P., Araujo, A. O., \& Lima, D. H. S. de. (2020). Metodologias ativas de ensino: evidências da aplicação do método de caso nos cursos de ciências contábeis e administração. Revista Mineira de Contabilidade, 20(3), 92-103.

Splitter, K., \& Borba, J. A. (2014). Percepção de estudantes e professores universitários sobre a profissão do contador: um estudo baseado na Teoria dos Estereótipos. Revista de Educação e Pesquisa em Contabilidade, 8(2), 126-141.

Tan, L. M., \& Laswad, F. (2018). Professional skills required of accountants: what do job advertisements tell us? Accounting Education, 27(4), 403-432.

Tibola, J. A., Silveira, A., \& Mais, I. (2012). Atributos de calidad en disciplinas de administración y ciencias contables dirigidas al estudio de costes: el punto de vista de los discentes. Revista de Educação e Pesquisa em Contabilidade, 6(4), 383-398.

Vergara, S. C., \& Ferreira, V. C. P. (2005). A representação social de ONGs segundo formadores de opinião do município do Rio de Janeiro. Revista de Administração Pública, 39(5), 1137-1159.

Watty, K., Jackling, B., \& Wilson, R. M. S. (2012). Personal transferable skills in Accounting Education. Routledge.

Wessels, P. L., \& Steenkamp, L. P. (2009). An investigation into students' perceptions of accountants. Meditari Accountancy Research, 17(1), 117-132. 